\title{
Country Portfolio Model Considering Market Uncertainties in Construction Industry
}

\author{
Won Jin Woo ${ }^{\text {a }}$, Seung-Heon Han ${ }^{\text {b*, Woosik Jang }}$, \\ ${ }^{a}$ Department of Civil and Environmental Engineering in Yonsei University, Seodaemun-gu, Seoul and 03722, Republic of Korea \\ ${ }^{b}$ Korea Institute of Civil Engineering and Building Technology, Ilsanseo-gu, Goyang-si, Gyeonggi-do and 10223, Republic of Korea \\ ${ }^{c}$ Department of Civil and Environmental Engineering in Chosun University, Dong-gu, Gwangju and 61452, Republic of Korea
}

\begin{abstract}
In recent decades, market uncertainties such as unpredicted economic recessions and expansions have significantly affected to the international construction market. These uncertainties arise simultaneously either at the country level or more broadly and traditional project-based risk management has limited to manage a contractor' profit. From the perspective of managing the market uncertainties, therefore, this study proposes country portfolio model that provides an optimized country portfolio solution through considering on the market outlook, country risk and expected profitability. These are evaluated by country-specific data related construction market and actual project performance data using monte-carlo simulation and genetic algorism. It is expected that the proposed country portfolio model will support to decide better decision about entering new international construction market by giving the ideal country portfolio considering market uncertainties.
\end{abstract}

(c) 2018 The Authors. Published by Diamond Congress Ltd., Budapest University of Technology and Economics Peer-review under responsibility of the scientific committee of the Creative Construction Conference 2018.

Keywords: Country Portfolio; Markrt uncertaity; International constrcution market.

\section{Introduction}

In recent decades, market uncertainties such as unpredicted economic recessions and expansions have significantly affected to the international construction market. In general, these uncertainties arise simultaneously either at the country level or more broadly [1] (e.g., the Asian financial crisis and the global financial crisis); In addition, since the construction business is an order-based industry, unlike other businesses such as manufacturing, the success or failure of a project is highly influenced by the uncertainties which is caused by characteristics of the host country and its clients. Thus, traditional project-based risk management has limited to manage a contractor's profit [1]. In such rapidly changing and highly uncertain host country environments, diversification is one of the strategic decisions made by international construction firms to manage market uncertainties. There are many studies is conducted the construction market risk and diversification. However, there are still questions about how to manage market uncertainties. Therefore, there is a need to study which is to control market uncertainties through a better country portfolio. The purpose of study is to propose the country portfolio model considering market uncertainties in construction industry by using the monte-carlo simulation and genetic algorithm. This model can provide weight portion of countries among portfolio. 


\section{Research Methodology}

\subsection{Modeling Frameworks}

This study proposes country portfolio model that provides an optimized country portfolio solution based on the market outlook, country risk and expected profitability. The market outlook means how the market will change. In this model, it is assessed by construction market's growth rate and volatility of the market size. The country risk means the risk caused by nature of the host country which consists of the political risk, execution risk and institutional risk. it is assessed by the country risk score and volatility of the country risk. The expected profitability means what the profit will be and how the profit will change. it is assessed by the expected profit rate and volatility of profit performance.

The proposed model utilizes a monte-carlo simulation and genetic algorithm. The monte-carlo simulation is utilized to determine the probability distribution of country risk and expected profitability. From the probability distribution, the country risk score, volatility of country risk, expected profit rate and volatility of the profit performance is obtained. The genetic algorithm is utilized to provide an optimized country portfolio solution which is to maximize market growth rate and expected profit rate and while to minimize volatility of the market size, country risk score, volatility of country risk and volatility of profit performance.

\subsection{Data Collection}

To calculate the market outlook, country risk and expected profitability, this study collects the secondary data on candidate countries and actual project performance data. Country-specific data related construction market were collected from internationally reputable institutions, such as the World Bank [2], IHS Global Insight [3]. The project performance data were obtained from the International Contractors Association of Korea (ICAK) [4] which has information on international project performance of Korean companies. Furthermore, this study selected 14 countries which are United Arab Emirates, Taiwan, Germany, Malaysia, United States, Vietnam, Saudi Arabia, Singapore, UK, Oman, Kuwait, Thailand, Pakistan, Philippines. There are two reasons for choosing these countries. One is that these countries are belonged as main or promising countries in Korea. The other reason is the data availability.

\section{The Proposed Country Portfolio Model}

\subsection{Market Outlook}

The market outlook is dealt with how the market will change. It consists the construction market's growth rate and volatility of the market size

The construction market's growth rate means the expected construction spending growth [5]. This study utilizes the forecasted data of the size of each construction market in the Global Construction Database provided by IHS Global Insight [3]. The construction market's growth rate is measured by the compound annual growth rate (CAGR) from 2014-2019.

Volatility of the market size is a concept that is contrary to construction market stability. Volatility of the market size [6] is measured by the percentage of construction market volatility $(\sigma)$ using IHS Global Insight [3] data for each construction market size over ten years (2007-2016);

$$
\operatorname{Volatility}(\sigma)=\sqrt{\frac{1}{n-1} \sum_{i=1}^{n}\left(x_{i}-\bar{x}\right)^{2}}, \quad\left(x_{i}=\ln \frac{s_{i}}{s_{i-1}}\right)
$$

Where $S_{i}=$ the construction market size at i year,

$\bar{x}=$ average of $x_{i}$

and $\mathrm{n}=$ the size of the construction market size data set

The construction market's growth rate (CAGR) and volatility of the market size are derived as followed Table 1 . 
Table 1. Market outlook, Country risk and Expected profitability of candidate countries

\begin{tabular}{|c|c|c|c|c|c|c|}
\hline \multirow[b]{2}{*}{ Country } & \multicolumn{2}{|c|}{ Market outlook } & \multicolumn{2}{|c|}{ Country risk } & \multicolumn{2}{|c|}{ Expected profitability } \\
\hline & $\begin{array}{c}\text { Growth Rate } \\
\text { (CAGE) }\end{array}$ & $\begin{array}{c}\text { Volatility } \\
\left(\sigma_{o}\right)\end{array}$ & Risk Score & $\begin{array}{c}\text { Volatility } \\
\left(\sigma_{r}\right)\end{array}$ & Profit & $\begin{array}{c}\text { Volatility } \\
\left(\sigma_{p}\right)\end{array}$ \\
\hline United Arab Emirate (UAE) & 0.0779 & 0.1343 & 3.0498 & 0.1776 & 0.0432 & 0.1616 \\
\hline Taiwan & 0.0778 & 0.1124 & 2.4885 & 0.2001 & 0.0811 & 0.1319 \\
\hline Germany & 0.0514 & 0.0762 & 1.9006 & 0.0595 & 0.1088 & 0.1237 \\
\hline Malaysia & 0.0849 & 0.0846 & 2.9925 & 0.1612 & 0.0371 & 0.1382 \\
\hline United Stated of America (USA) & 0.0799 & 0.0971 & 1.9087 & 0.1475 & 0.0877 & 0.1309 \\
\hline Vietnam & 0.1226 & 0.0464 & 4.6659 & 0.1212 & 0.0697 & 0.1719 \\
\hline Saudi Arabia & 0.0769 & 0.0429 & 4.1084 & 0.2623 & 0.0473 & 0.1511 \\
\hline Singapore & 0.0754 & 0.1306 & 1.4703 & 0.193 & 0.0303 & 0.1168 \\
\hline United Kingdom (UK) & 0.0879 & 0.1408 & 1.5799 & 0.1084 & 0.1163 & 0.1648 \\
\hline Oman & 0.0696 & 0.1353 & 3.7269 & 0.1448 & 0.0314 & 0.305 \\
\hline Kuwait & 0.0307 & 0.1559 & 4.4204 & 0.0899 & 0.0467 & 0.1673 \\
\hline Thailand & 0.0872 & 0.0716 & 3.6077 & 0.1276 & 0.0529 & 0.1462 \\
\hline Pakistan & 0.0681 & 0.0964 & 5.3658 & 0.1588 & 0.0326 & 0.2541 \\
\hline Philippines & 0.0916 & 0.0929 & 4.66 & 0.1981 & 0.0579 & 0.1615 \\
\hline
\end{tabular}

\subsection{Country Risk}

In general, country risk has only been evaluated or considered as a discrete value provided by WGI, DBI, BMI and the other data source. However, when the countries have similar risk levels, it is necessary to evaluate the country by considering the volatility of country risks rather than the subtle risk differences.

To take account of this uncertainty, country risk is calculated with the political risk, executional risk and institutional risk by using monte-carlo simulation. The calculation process is consisted 4 steps.

First step is to calculate the political risk value which explains each country's level of maturity and political stability. It is evaluated by using the worldwide governance indicators (WGI) provided by the World Bank [2]. WGI provide the estimate score (the high estimate score means high quality) and the standard deviation of six factors: voice and accountability; political stability and absence of violence; government effectiveness; regulatory quality; rule of law; and control of corruption. In order to express the uncertainty of political risk, monte-carlo simulation is conducted. The political risk value is derived by summing the probability distributions for each six dimension factors by applying the normal distribution( $\sim$ (factor's estimate score, factor's standard deviation)).

Second step is to calculate the executional risk value which explains each country's level of business efficiency and flexibility. This risk is measured by using the doing business indicators provided by the World Bank [2]. It consists ten factors: starting a business; dealing with construction permits; getting electricity; registering property; getting credit; protecting minority investors; paying taxes; trading across borders; enforcing contracts; and resolving insolvency. In order to express the uncertainty of executional risk, monte-carlo simulation is also conducted. However, since DBI don't provide the standard deviation unlike WGI, the probability distribution is derived by data fitting which is fitting the overall distance to frontier (DTF) scores from 2008 - 2017(See Fig. 1). The DTF means the business efficiency and flexibility (the high DTF score means high efficiency). The criterion of choosing the probability distribution is the Akaike Information Criterion(AIC) and subjective opinion based on the form of data set. 


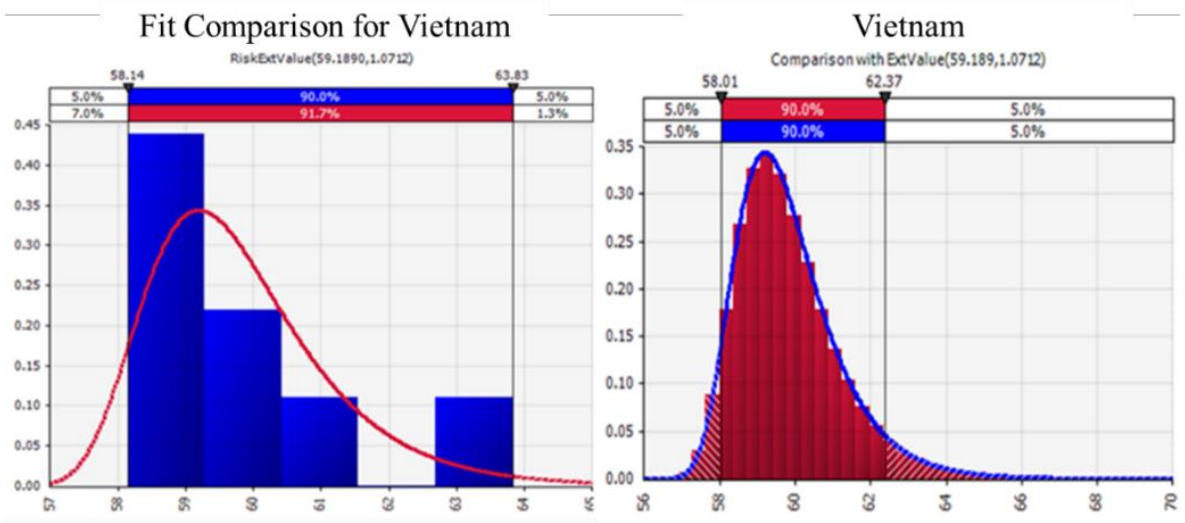

Fig. 1. The probability distribution of Vietnam execution risk value.

Third step is to calculate institutional risk value which explains each country's level of institutional maturity. This risk is measured by using institutional profiles database (IPD). Since there is no data to define the probability distribution, this risk is used the discrete value to calculate the country risk.

Final step is to calculate the country risk value. The country risk value is derived by summing the three risk values which is political, executional and institutional risk values and it is subtracted from 10. The equation as follows:

$$
\begin{aligned}
& \text { Country risk value }=10-\left(w_{p} S_{p}+w_{e} S_{e}+w_{i} S_{i}\right) \\
& w_{p}+w_{p}+w_{p}=1
\end{aligned}
$$

Where $S_{P}=$ value of political risk,

$w_{p}=$ weight of political risk value

$S_{e}=$ value of executional risk

$w_{e}=$ weight of executional risk value

$S_{i}=$ value of institutional risk

and $w_{i}=$ weight of institutional risk value

From the country risk value's probability distribution, the country risk score which is the mean of the probability distribution and volatility of the country risk which is the standard deviation of the probability distribution are derived as followed Table 1. (Weight is assumed that the $w_{p}$ is $0.3, w_{p}$ is 0.6 and $w_{p}$ is 0.1 )

As shown in Fig. 2, you can see why considering the volatility is necessary. If decision-maker simply compare the risk scores, Singapore may be a better country than the UK. However, in terms of volatility, the UK is more stable than Singapore because Singapore is more likely to higher risk scores than the UK.
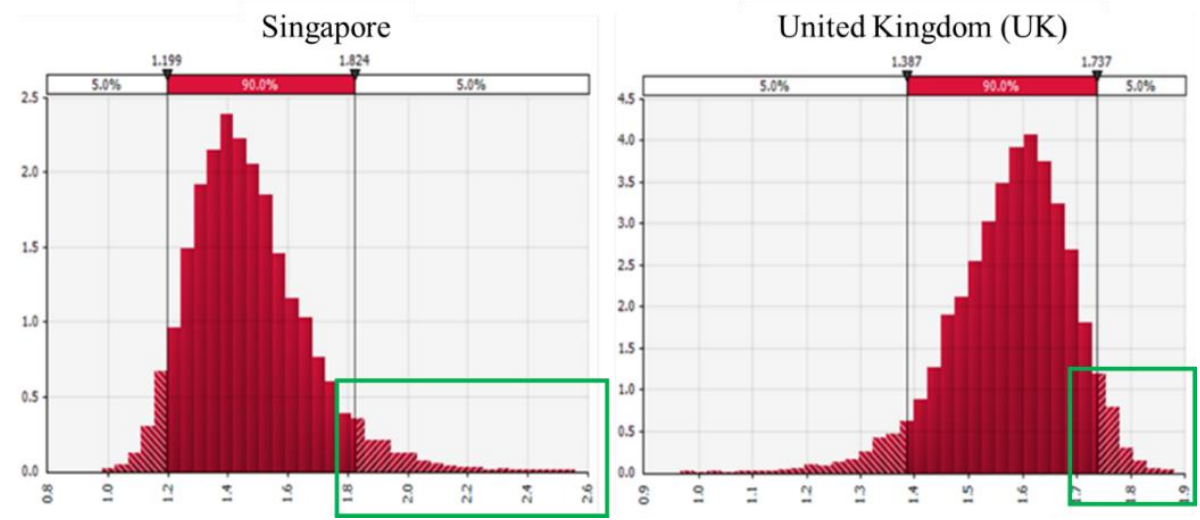

Fig. 2. The country risk probability distribution (Singapore, United Kingdom). 
The sensitivity analysis is also conducted (see Fig. 3). Although sensitivity analysis results were different for each country, in most countries (except Germany, Kuwait), the sensitivity of executional risk is greater than that of political risk. The main reason for this result is that the weight of executional risk is higher than that of political risk. The sensitivity analysis results will change with each weight change.

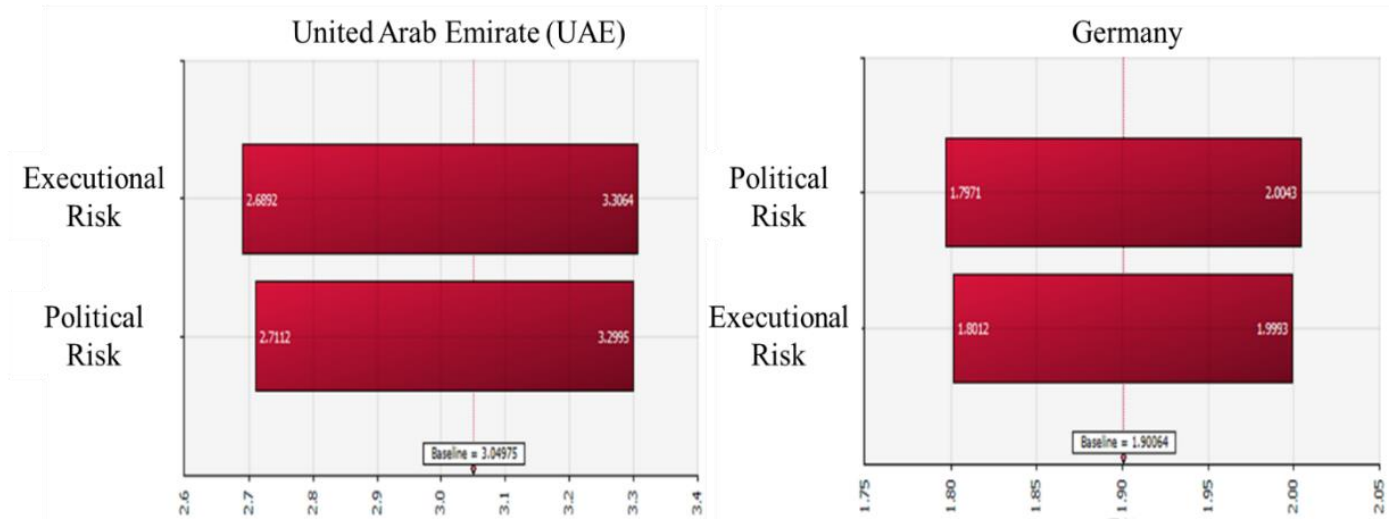

Fig. 3. The result of Sensitivity analysis (UAE, Germany)

\subsection{Expected profitability}

Expected profitability is measured by using the actual international engineering and construction project profit data [4] executed by Korea contractors across 14 countries over the past 25 years. In order to obtain the expected profit rate and volatility of profit performance, the probability distribution is derived by data fitting (Fig.4). This study removes some data which are too much higher, lower and zero profit rate to improve the Data fitting quality. The criterion of choosing the probability distribution is the Akaike Information Criterion(AIC) and subjective opinion based on the form of data set.

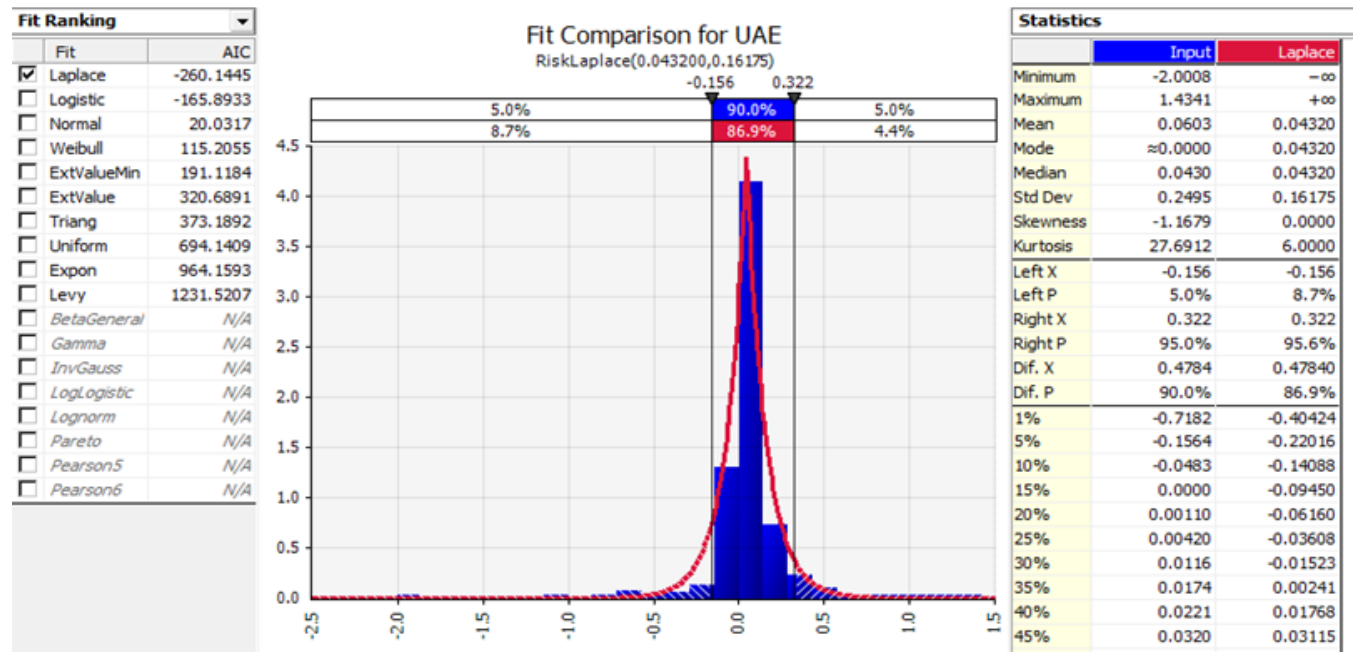

Fig. 4. The probability distribution of UAE profit performance

From this probability distribution, the expected profitability which is the mean of the probability distribution and volatility of project performance which is the standard deviation of the probability distribution are derived as followed Table 1. 


\subsection{Country portfolio solution from Genetic algorithm}

This study develops the objective functions to find the best portfolio solutions that maximize market growth rate and expected profit rate and while to minimize volatility of the market size, country risk score, volatility of country risk and volatility of profit performance.

Before conducting genetic algorithm, this study uses the standard deviation method to calculate variables with the same dimension (standardized score). The standardized score of variable $\left(Z_{V_{i}}\right)$ is calculated as follows:

$$
Z_{V_{i, j}}=\frac{V_{i, j}-\mu_{i, j}}{\sigma_{i, j}}
$$

Where $V_{i, j}=$ the original value of variable $\mathrm{i}$ in country $\mathrm{j}$,

$\mu_{i, j}=$ the average value of variable $\mathrm{i}$ in country $\mathrm{j}$,

and $\sigma_{i, j}=$ the standard deviation for variable $\mathrm{i}$ in country $\mathrm{j}$.

The objective function as shown in the following equations:

Minimize $\cdot f(x)=-\sum_{i=1}^{n} x_{i} Z_{V_{1, i}}+\sum_{i=1}^{n} x_{i} Z_{V_{2, i}}+\sum_{i=1}^{n} x_{i} Z_{V_{3, i}}+\sum_{i=1}^{n} x_{i} Z_{V_{4, i}}-\sum_{i=1}^{n} x_{i} Z_{V_{5, i}}+\sum_{i=1}^{n} x_{i} Z_{V_{6, i}}$

Where $f=$ market portfolios (x)

$x_{i}=$ weight portion of country $i$ among the portfolios

$Z_{V_{1, i}}=$ The standardized score of market growth rate

$Z_{V_{2, i}}=$ The standardized score of volatility of market size

$Z_{V_{3, i}}=$ The standardized score of country risk score

$Z_{V_{4, i}}=$ The standardized score of volatility of country risk

$Z_{V_{5, i}}=$ The standardized score of expected profit rate

$Z_{V_{6, i}}=$ The standardized score of volatility of profit performance

and $\mathrm{n}=$ Number of country

The Constraint conditions as shown in the following equations:

$$
\begin{aligned}
& \sum_{i=1}^{n} x_{i}=1 \\
& 0 \leq x_{i} \leq 1
\end{aligned}
$$

Under these conditions, the genetic algorithm is conducted. This model can find out optimal solution within 70 iterations (see Fig.5) and the weight portion of each country is derived (see Table 2). The result means that if decisionmaker want to maximize market growth rate and expected profit rate and while to minimize volatility of the market size, country risk score, volatility of country risk and volatility of profit performance, He or she should allocate highest weight portion of Vietnam among the portfolios.

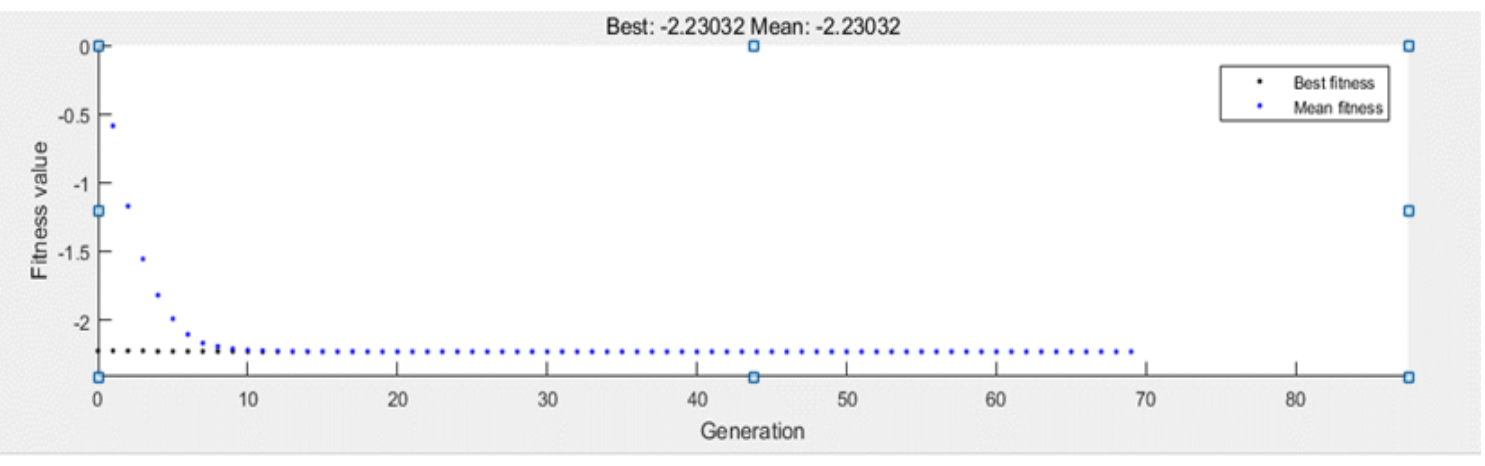

Fig. 5. The result of Genetic Algorithm (plot the fitness value) 
Table 2. Weight portion of country among the portfolios

\begin{tabular}{lc}
\hline \multicolumn{1}{c}{ Country } & Weight portion \\
\hline United Arab Emirate (UAE) & $0.20 \%$ \\
Taiwan & $3.00 \%$ \\
Germany & $5.10 \%$ \\
Malaysia & $2.90 \%$ \\
United Stated of America (USA) & $2.10 \%$ \\
Vietnam & $67.70 \%$ \\
Saudi Arabia & $2.80 \%$ \\
Singapore & $2.40 \%$ \\
United Kingdom (UK) & $3.50 \%$ \\
Oman & $0.20 \%$ \\
Kuwait & $0.00 \%$ \\
Thailand & $2.50 \%$ \\
Pakistan & $3.50 \%$ \\
Philippines & $4.30 \%$ \\
\hline
\end{tabular}

\section{Discussion and Conclusion}

In rapidly changing and highly uncertain host country environments, diversification is one of the strategic decisions made by international construction firms to manage market uncertainties. From the perspective of managing the market uncertainties, this study proposes country portfolio model that provides an optimized country portfolio solution based on the market outlook, country risk and expected profitability by using monte-carlo simulation and genetic algorithm. The model's final output is weight portion of country among the portfolios. There are some advantages. First advantage is that this model is possible to support decision makers by presenting probability distributions rather than simple discrete values through monte-carlo simulation. Second it model can help to make a more accurate portfolio solution considering the uncertainty of county risk. Furthermore, since it uses accessible data such as WGI, DBI, GI and so on, it has an advantage that it can be easily used by anyone.

However, there are many limitations. The variables to be considered are too few and simple to make a country assessment. For example, competitiveness of order and intensity of competition are very important factors in country assessment, but they do not reflect these. Also, since the model is constructed by relying on general data, it is less usability in practical area. Finally, the objective function and constraint conditions are too simple.

There are a lot of variables and uncertainties which affect the country assessment. In the future study, if a model is developed that can be analyzed by adding unobserved variables such as competitive strength and the characteristics of country such as experience, host government, I think it can be used as a support tool. Also, from the optimization point of view, I think that it can be a good model if a more realistic optimal function and constraint is set.

\section{Acknowledgements}

This work was supported by a grant funded by Ministry of Land, Infrastructure and Transport of Korean government (18SCIP-C079445-05)

\section{References}

[1] Jung, W., Han, S. H., \& Lee, K. W., Country portfolio solutions for global market uncertainties. J. Manage. Eng. 28 (2011), $372-381$.

[2] World Bank. (2018). "World Bank open data." hhttp://data.worldbank.org/i

[3] IHS Global Insight. Global construction outlook, (2017). Lexington, MA.

[4] ICAK (International Contractors Association of Korea). "International construction information service.", (2018) <hhttp://www.icak.or.kr/>

[5] Lee, K. W., \& Han, S. H., Quantitative analysis for country classification in the construction industry. J. Manage. Eng. 33 (2017), 04017014.

[6] Luenberger, D. G. (1998). Investment science, Oxford University Press, New York. 